\title{
Experimental Pharmacology in Transgenic Rodent Models of Alzheimer's Disease
}

\section{A. Claudio Cuello ${ }^{1,2,3 *+}$, Hélène Hall't and Sonia Do Carmo ${ }^{1}$}

${ }^{1}$ Department of Pharmacology and Therapeutics, McGill University, Montreal, QC, Canada, ${ }^{2}$ Department of Neurology and Neurosurgery, McGill University, Montreal, QC, Canada, ${ }^{3}$ Department of Anatomy and Cell Biology, McGill University, Montreal, QC, Canada

This Mini Review discusses the merits and shortfalls of transgenic (tg) rodents modeling aspects of the human Alzheimer's disease (AD) pathology and their application to evaluate experimental therapeutics. It addresses some of the differences between mouse and rat tg models for these investigations. It relates, in a condensed fashion, the experience of our research laboratory with the application of anti-inflammatory compounds and S-adenosylmethionine (SAM) at the earliest stages of AD-like amyloid pathology in $\operatorname{tg}$ mice. The application of SAM was intended to revert the global brain DNA hypomethylation unleashed by the intraneuronal accumulation of amyloid-
OPEN ACCESS

Edited by:

Salvatore Salomone,

Università degli Studi di Catania, Italy

Reviewed by:

Gaurav Bedse,

Vanderbilt University Medical Center,

United States

Oliver Wirths,

University Medical Center Göttingen,

Germany

*Correspondence:

A. Claudio Cuello

claudio.cuello@mcgill.ca

${ }^{\dagger}$ These authors have contributed

Specialty section:

This article was submitted to

Experimental Pharmacology

and Drug Discovery,

a section of the journal

Frontiers in Pharmacology

Received: 17 December 2018

Accepted: 14 February 2019

Published: 04 March 2019

Citation:

Cuello $A C$, Hall $\mathrm{H}$ and

Do Carmo S (2019) Experimental Pharmacology in Transgenic Rodent

Models of Alzheimer's Disease.

Front. Pharmacol. 10:189.

doi: 10.3389/fphar.2019.00189 equally to this work $\beta$-immunoreactive material, an intervention that restored levels of DNA methylation including of the bace1 gene. This review also summarizes experimental pharmacology observations made in the McGill tg rat model of AD-like pathology by applying "nanolithium" or a drug with allosteric M1 muscarinic and sigma 1 receptor agonistic properties (AF710B). Extremely low doses of lithium (up to 400 times lower than used in the clinic) had remarkable beneficial effects on lowering pathology and improving cognitive functions in tg rats. Likewise, AF710B treatment, even at advanced stages of the pathology, displayed remarkable beneficial effects. This drug, in experimental conditions, demonstrated possible "disease-modifying" properties as pathology was frankly diminished and cognition improved after a month of "wash-out" period. The Mini-Review ends with a discussion on the predictive value of similar experimental pharmacological interventions in current rodent tg models. It comments on the validity of some of these approaches for early interventions at preclinical stages of $A D$, interventions which may be envisioned once definitive diagnosis of $A D$ before clinical presentation is made possible.

Keywords: Alzheimer's disease, cholinergic, DNA hypomethylation, experimental therapy, neuroinflammation, lithium, muscarinic/sigma1 receptors, S-adenosyl methionine

\section{INTRODUCTION}

Alzheimer's disease $(\mathrm{AD})$ is a progressive neurodegenerative disease and the leading cause of dementia in the elderly (Hardy et al., 2014; Aisen et al., 2017). Postmortem brains from AD patients display characteristic pathological hallmarks, defined as extracellular amyloid plaques and intracellular neurofibrillary tangles made of hyper-phosphorylated tau protein. In addition, the cholinergic system is severely compromised. The vast majority of AD cases is sporadic, while $<1 \%$ of cases corresponds to autosomal dominant forms, or familial AD (FAD), in which specific genetic mutations drive disease onset (Bateman et al., 2011; Ryman et al., 2014). 
To date, there is no treatment to cure or prevent the development of the disease. Patients only have access to a few therapeutic options which offer limited symptomatic relief. Three of the four drugs approved by the Food and Drug Administration (FDA) for $\mathrm{AD}$ are cholinesterase inhibitors (AChEI). They enhance cholinergic synaptic transmission by preventing the breakdown of acetylcholine, a neurotransmitter essential for learning and memory. The fourth drug is memantine, an NMDA-receptor antagonist, while an additional pharmacological option combines one of the AChEI (donepezil) and memantine (Alzheimer's Association, 2018).

Although studies would indicate a decrease in the incidence of $\mathrm{AD}$ in high-income countries over the past 10 years (Langa, 2015; Derby et al., 2017; Seblova et al., 2018), it is unlikely to offset the aging population. In fact, $\mathrm{AD}$ prevalence is increasing worldwide and is reaching near-epidemic proportions (Hickman et al., 2016). In that context, it is urgent to develop new drugs that can halt or prevent the progression of the disease. As of January 30, 2018, there were 112 agents in the $\mathrm{AD}$ treatment pipeline registered on clinicaltrial.gov, $63 \%$ of which are disease-modifying therapies (Cummings et al., 2018), illustrating the current efforts devoted to finding a cure for AD. Preclinical studies constitute an important cornerstone in drug development; validation of drug safety and efficacy in animal models is a necessary step before moving a drug into clinical trials. As such, animal models are a critical component to move the research field forward.

In this review, we will provide a concise overview of transgenic (tg) rodent models mimicking key aspects of the AD pathology and discuss their value in the drug development pipeline, as well as the challenges to predict drug efficacy in $\mathrm{AD}$ patients based on animal studies. In particular, we will focus on our experience with our transgenic mouse and rat models and describe experimental pharmacology studies using these models.

\section{OVERVIEW OF TRANSGENIC MODELS OF ALZHEIMER'S DISEASE}

A large number of $\mathrm{tg}$ mice and rats reproducing key features of the AD pathology have been generated. As of December 2018, the Alzheimer Forum Website lists 160 tg rodent models in its online database ${ }^{1}$ (Kinoshita and Clark, 2007), 156 of which are mice and only 4 are rats. The majority of these models express human genes bearing mutations described in FAD cases and human tauopathies, as well as human genes identified by Genome Wide Association Studies as susceptibility genes increasing the risk of developing $\mathrm{AD}$ (Tosto and Reitz, 2013). As such, they mostly mimic rare familial forms of $\mathrm{AD}$ and may not provide data translatable to sporadic $\mathrm{AD}$. The most popular models are based on overexpression of human amyloid precursor protein (APP), presenilin (PSEN) [part of the $\gamma$-secretase complex involved in the cleavage of APP into amyloid- $\beta(\mathrm{A} \beta)]$ and tau, alone or in combination, to trigger accumulation of high

${ }^{1}$ https://www.alzforum.org/research-models/alzheimers-disease levels of $A \beta$ into plaques as well as the development of tauopathy (Spires and Hyman, 2005).

In particular, the most frequently used mouse models have been mice overexpressing human APP with the double Swedish (K670N and M671L) (Mullan et al., 1992) and the Indiana (V717F) (Murrell et al., 1991) mutations, such as the PDAPP (Games et al., 1995), tg2576 (Hsiao et al., 1996) and J20 (Mucke et al., 2000) models, as well as mice overexpressing mutant human APP and PSEN such as the APP/PS1 (Holcomb et al., 1998) and 5xFAD (Oakley et al., 2006) mice. One of the most popular mouse models to date is the $3 \times \mathrm{Tg}$ model harboring mutated APP, PSEN and tau genes (Oddo et al., 2003). In parallel, mouse models of tauopathies, in particular the hTauP301S (Allen et al., 2002) and PS19 mice (Yoshiyama et al., 2007), have become popular to study the tau component of the AD pathology (Gotz et al., 2007), although their main limitation resides in the expression of human tau harboring mutations seen in frontotemporal dementia and parkinsonism linked to chromosome 17 and not in $\mathrm{AD}$. The particular characteristics and merits of tg mice for $\mathrm{AD}$ research have been discussed in several reviews (Hsiao, 1998; Bales, 2012; LaFerla and Green, 2012; Puzzo et al., 2015; Ameen-Ali et al., 2017; Jankowsky and Zheng, 2017; Sasaguri et al., 2017).

The most frequently used tg rats modeling the $\mathrm{AD}$-like amyloid pathology are the McGill-R-Thy1-APP (Leon et al., 2010) and TgF344-AD (Cohen et al., 2013) rats. The clear imbalance in the ratio of mouse/rat models of $\mathrm{AD}$ reflects the inherent difficulty of producing tg rats in the early years of transgenesis, rather than an advantage of mice over rats. However, advances in transgenesis techniques have had a substantial impact on the development of tg rats (Filipiak and Saunders, 2006). In fact, rats are better suited than mice for biomedical research relevant to human. The increased value of rats over mice to study, in particular, human neurodegenerative conditions has been highlighted in recent reviews, with an emphasis on cognitive outcomes (Do Carmo and Cuello, 2013) and brain imaging (Zimmer et al., 2014). More recently, Drummond and Wisniewski (2017) discussed the relative characteristics of diverse species for a better representation of the human $\mathrm{AD}$ pathology and the challenges ahead.

$\mathrm{Tg}$ rodent models of $\mathrm{AD}$ have undoubtedly provided invaluable insights into the pathological processes of AD. They have also been instrumental in moving experimental therapy into clinical trials, following reports of positive therapeutic outcomes in rodent models. In this context, tg models played a pivotal role in the development of immunotherapy for $\mathrm{AD}$, following the first experimental evidence that immunization of PDAPP mice with fibrillary $A \beta_{42}$ decreased amyloid pathology (Schenk et al., 1999). Subsequent studies demonstrated that vaccination with $A \beta$ also prevented memory loss in tg mouse models of AD (Janus et al., 2000; Morgan et al., 2000), which rapidly led to clinical trials. The first of these trials was unfortunately prematurely halted after a subset of patients developed acute meningoencephalitis (Orgogozo et al., 2003). Since then, more than one thousand publications have emerged illustrating efficacy, in varying degrees, of a large range of 
compounds. Some of these experimental attempts have been reviewed in LaFerla and Green (2012) and Sasaguri et al. (2017).

\section{PHARMACOLOGICAL THERAPY IN MOUSE AND RAT MODELS OF THE AD-LIKE AMYLOID PATHOLOGY - INSIGHTS FROM OUR EXPERIENCE}

Our laboratory has developed tg lines expressing human APP with the double Swedish and the Indiana mutations under the Thyl promoter, which recapitulate key features of the $\mathrm{AD}$-like amyloid pathology in mice and rats. The McGill-Thyl-APP mice (Ferretti et al., 2011) and McGill-R-Thy1-APP rats (Leon et al., 2010) have been extensively studied by us (Cuello et al., 2010, 2012; Ferretti et al., 2012a,b; Hanzel et al., 2014; Iulita et al., 2014, 2017; Pimentel et al., 2015; Do Carmo et al., 2016, 2018; Wilson et al., 2017a,b, 2018; Hall et al., 2018) and others (Nilsen et al., 2012, 2014a,b; Galeano et al., 2014, 2018; Qi et al., 2014, 2018; Heggland et al., 2015; Martino Adami et al., 2017a,b; Parent et al., 2017; Zhang et al., 2017; Prestia et al., 2018). In the following section, we will discuss the particular value of these specific models in experimental pharmacology.

\section{McGill-Thy1-APP Mice}

In the McGill-Thyl-APP mouse model, overexpression of mutant human APP triggers intraneuronal accumulation of $A \beta$ material, including $A \beta$ oligomers and fibrillary oligomers in cortical and hippocampal pyramidal neurons. Cognitive deficits are present prior to deposition of extracellular amyloid plaques at 4 months of age. At the same time, cholinergic alterations are detected in the cerebral cortex. Levels of insulin degrading enzyme, a well-established $\mathrm{A} \beta$ degrading enzyme, are downregulated in the cerebral cortex, suggesting that an impaired clearance of $A \beta$ material likely contributes to the $A \beta$ accumulation (Ferretti et al., 2011). In addition, microglial activation and recruitment toward $\mathrm{A} \beta$-burdened neurons is present before plaque formation, along with an upregulation in major histocompatibility complex II, inducible nitric oxide (i-NOS) and CD40. This pre-plaque proinflammatory process is also accompanied by neuronal cyclooxygenase-2 (COX-2) upregulation (Ferretti et al., 2012b).

\section{Minocycline}

At late, clinical stages of $\mathrm{AD}$, there is well-characterized chronic CNS inflammation. This late neuroinflammatory process is characterized by a strong immune response and phagocytic removal of $A \beta$ material (McGeer and Rogers, 1992; McGeer and McGeer, 2013). These findings and the evidence that long term NSAIDs treatment for rheumathoid arthritis diminished AD prevalence (McGeer et al., 1990) sparked the idea that therapeutic agents directed at lowering inflammation could be of benefit for $\mathrm{AD}$ patients. However, studies showed that antiinflammatories administered after $\mathrm{AD}$ clinical presentation did not improve cognitive decline (Jaturapatporn et al., 2012). In contrast, a large number of epidemiological studies confirmed that cognitively normal individuals receiving long term antiinflammatory medication had a reduced risk of developing $\mathrm{AD}$ when compared to the general population (Breitner et al., 2011; McGeer and McGeer, 2013; Zhang et al., 2018). Taken together, these apparent contradictory findings support the idea that CNS inflammation at early (preclinical) and late (clinical) stages of $\mathrm{AD}$ are fundamentally distinct processes and suggest that blunting the early disease-aggravating inflammatory process may be of benefit for $\mathrm{AD}$ patients, concepts that have been further discussed in an opinion paper in TIPS (Cuello, 2017) and in a "white paper" in Alzheimer's and Dementia by Rogers (2018).

As detailed in the previous section, McGill-Thy1-APP mice display an early pre-plaque disease-aggravating neuroinflammatory process (Ferretti et al., 2011) which, according to the above, may constitute an interesting target for therapeutic intervention. To test this hypothesis, and supported by prior observations (Seabrook et al., 2006), tg mice were treated with minocycline, a tetracyclic derivative with anti-inflammatory properties, at a young, pre-plaque stage, for one month. Minocycline treatment corrected the upregulation of i-NOS and COX-2, lowered interleukin- $1 \beta$ levels and decreased microglial activation. The reduction in inflammation was accompanied by changes in the APP processing, namely a decrease in full length APP and A $\beta$ trimer levels, while the activity of the $\beta$-site APP cleaving enzyme 1 (BACE1) was normalized (Ferretti et al., 2012a). Overall this study demonstrates that the early, pre-plaque, disease aggravating neuroinflammatory process triggered by the $\mathrm{AD}$-like amyloid pathology can be dampened by the pharmacological application of minocycline.

These findings would support the notion that targeting inflammation early in the disease process should have a beneficial outcome in individuals with preclinical AD pathology. Successful implementation of such a strategy will, however, rely on the unequivocal identification of biomarkers of $\mathrm{AD}$ preclinical stages.

\section{S-Adenosylmethionine (SAM)}

There is growing evidence revealing that epigenetic deregulations and dysregulated DNA methylation may unleash diseaseaggravating mechanisms in several neuropathologies. AD patients and $\mathrm{AD}$ animal models display global and gene-specific DNA hypomethylation within the brain (West et al., 1995; Mastroeni et al., 2010; Bakulski et al., 2012; Chouliaras et al., 2013; Cadena-del-Castillo et al., 2014; De Jager et al., 2014; Iwata et al., 2014; Smith et al., 2016; Nicolia et al., 2017; Zhao et al., 2017), likely contributing to the AD pathology and associated memory deficits. We have demonstrated the occurrence of global DNA hypomethylation, which is prominent in neurons, at early pathological stages in McGill-Thy1-APP mice. Importantly, the bace1 promoter is hypomethylated in our tg mice. This was associated with higher levels of BACE1 protein and BACE1 activity, and in consequence increased $A \beta$ peptides in the CNS (Do Carmo et al., 2016).

The cause of global hypomethylation in $\mathrm{AD}$ remains unclear. However, we found that early intraneuronal accumulation of $\mathrm{A} \beta$ is sufficient to provoke global DNA hypomethylation (Do Carmo et al., 2016). Importantly, in AD patients the levels of the ubiquitous methyl donor S-adenosylmethionine (SAM) are low in the brain and cerebrospinal fluid (Bottiglieri et al., 1991; Morrison et al., 1996). This prompted us to administer 
systemically SAM to McGill-Thy1-APP mice, starting at early stages of the pathology. This straightforward therapy was sufficient to abolish the pre-existing global hypomethylation, as well as bace 1 hypomethylation. BACE1 protein levels and activity were restored to control levels and brain amyloid pathology decreased. This strategy was sufficient to fully revert the cognitive impairment consequent to the CNS amyloid pathology, as revealed by the novel object recognition (NOR) and the Morris water maze (MWM) tests (Do Carmo et al., 2016). The findings, in our model, of an early neuronal demethylation and its rescue by SAM treatment reinforce a causal link between $A \beta$ accumulation and impaired DNA methylation, rather than the consequence of stochastic events.

In addition, in human brains from the Religious Orders Study cohorts, we also found correlations between bace1 methylation levels and amyloid and tangle load as well as measures of cognition (Do Carmo et al., 2016). Overall, our observations in tg mice and $\mathrm{AD}$ patients suggest that DNA hypomethylation should be considered as a drugable target for the treatment of $\mathrm{AD}$, and that, in consequence, SAM-based therapy might constitute a promising therapeutic avenue. Of note, the use of SAM in the treatment of multiple neuropsychiatric disorders is currently being explored (Sharma et al., 2017).

\section{McGill-R-Thy1-APP Rats}

The McGill-R-Thy1-APP rats display early intraneuronal accumulation of $A \beta$ in the hippocampus and cerebral cortex, evident one week after birth. As the amyloid pathology progresses with age, extracellular plaques start to develop. The first plaques are observed in the subiculum at 6-9 months of age (Leon et al., 2010) and later spread through anatomically connected regions (Heggland et al., 2015). Cognitive deficits are apparent at 3 months of age and worsen as the pathology progresses (Leon et al., 2010). This evolving pathology is accompanied by an early, disease-aggravating, pre-plaque neuroinflammatory process (Hanzel et al., 2014). Deficits in synaptic plasticity are evident at the pre-plaque stage and appear to be inflammasome-dependent (Qi et al., 2014, 2018). Similarly, deficits in synaptosomal bioenergetics are reported before the appearance of plaques (Martino Adami et al., 2017b). At the post-plaque stage, the NGF metabolic pathway is dysregulated and shows impairment in neurotrophin expression (Iulita et al., 2017), as seen during the progression of AD in patients (Iulita and Cuello, 2016). These changes are accompanied by a reduction in cholinergic synaptic boutons (Iulita et al., 2017). Moderate neuronal loss in the subiculum (Heggland et al., 2015), hippocampal shrinkage and glucose hypometabolism further characterize the post-plaque stage (Parent et al., 2017). Overall, in the McGill-R-Thy1-APP rat model, a slowly evolving amyloid pathology triggers a cascade of events reminiscent of what is seen in AD brains, thereby offering an array of targets possibly amenable to therapeutic intervention.

\section{NP03-Lithium}

The complex nature of the human $\mathrm{AD}$ pathology, which involves multiple processes such as abnormal $\mathrm{A} \beta$ and tau processing, CNS inflammation, mitochondrial dysfunction and calcium dyshomeostasis, calls for the use of multi-target drugs rather than a compound targeting a single molecule. In that context, lithium is of interest as it reportedly has the ability to modulate several of these pathways (Malhi and Outhred, 2016).

Lithium salts are widely used in the treatment of psychiatric conditions such as bipolar disorder. A limited number of studies have also examined the potential use of lithium in amnestic mild cognitive impairment and clinical AD populations, and have reported promising but often conflicting results (Havens and Cole, 1982; Terao et al., 2006; Macdonald et al., 2008; Hampel et al., 2009; Leyhe et al., 2009; Forlenza et al., 2011, 2016; Nunes et al., 2013; Mauer et al., 2014; Morris and Berk, 2016; Kessing et al., 2017). Unfortunately, lithium has a narrow therapeutic window and a low brain penetration. It elicits with some frequency severe side effects which limit its long-term use in the elderly population (Gelenberg and Jefferson, 1995; Livingstone and Rampes, 2006; Azab et al., 2015). Coincidently with the finding that trace amounts of lithium in drinking water are associated with a reduced incidence of dementia (Mauer et al., 2014; Kessing et al., 2017; McGrath and Berk, 2017; Fajardo et al., 2018), there has been a growing interest for low-dose lithium in the treatment of AD (Nunes et al., 2013, 2015; Zhao et al., 2014). Treatment with microdose lithium was shown to prevent cognitive decline in $\mathrm{AD}$ patients and in $\mathrm{AD}$ tg models (Nunes et al., 2013, 2015).

NP03 is a novel formulation of lithium, in which microdose lithium is encapsulated in a water-in-oil microemulsion (Aonys technology developed by Medesis Pharma, Montpellier, France). This formulation can enhance the CNS penetration of significantly lower amounts of lithium, with doses 100 to 400 times lower than what is usually prescribed for bipolar disorder. Such doses can most likely avoid the adverse effects associated with classical, higher dosage, lithium formulations. Treatment of young, pre-plaque McGill-R-Thyl-APP rats with NP03 resulted in cognitive improvements as measured by the NOR, MWM and fear conditioning tests. Unexpectedly, NP03 treatment also reduced BACE1 levels and activity, leading to a decrease in levels of soluble A $\beta 42$. NP03 treatment was also shown to inactivate GSK-3 $\beta$, rescue impaired CRTC1 promoter binding of synaptic plasticity genes and restore hippocampal neurogenesis in tg rats (Wilson et al., 2017b). In addition, NP03 reduced oxidative stress and inflammation markers in tg rats, as evidenced by decreased levels of protein-bound 4-hydroxynonenal and protein-resident 3 -nitrotyrosine, as well as reduced production of cytokines such as TNF- $\alpha$, IFN- $\gamma$, IL-10, and IL-5. Finally, NP03 downregulated transcripts levels of the microglia surface receptor TREM2 concomitantly with a reduced recruitment of microglia toward A $\beta$-burden neurons in the hippocampus (Wilson et al., 2018). These findings highlight the value of novel formulations of non-toxic microdose lithium NP03 in the treatment of AD at its early, preclinical, stages.

\section{Combined M1 Muscarinic/Sigma 1 Receptor Agonist}

In the early 1990s, a pivotal study demonstrated that activation of muscarinic cholinergic receptors could modulate the APP processing toward a non-amyloidogenic pathway (Nitsch et al., 1992), thereby reducing the production of toxic $A \beta$. It was later shown that the M1 muscarinic receptors in particular 
played a key role in modulating the AD-like amyloid pathology in vivo (Caccamo et al., 2006). Following these seminal discoveries, it was hypothesized that M1 receptor agonists could extend the cholinergic-based therapeutic arsenal for AD: they should, not only enhance the cholinergic tone for the cognitive benefits of $\mathrm{AD}$ patients, but also provide diseasemodifying properties. Unfortunately, first generation muscarinic agonists lacked specificity for the M1 receptors, and activation of other receptor subtypes led to major side effects (Fisher, 2008). However, the generation of novel subtype specific muscarinic agonists has renewed the interest for this type of compounds (Fisher, 2012).

Given the complexity of $\mathrm{AD}$ pathophysiology, drugs that can target multiple receptors or impaired signaling pathways would likely offer a therapeutic advantage over more conventional single-target drug, as illustrated in the previous section. In that regards, the novel compound AF710B (aka ANAVEX 371) merits further attention. It is a combined selective allosteric M1 muscarinic and sigma 1 receptor agonist (Fisher et al., 2016). Targeting sigma 1 receptor has been shown to provide neuroprotection and anti-amnestic properties (Marrazzo et al., 2005; Maurice and Su, 2009; Villard et al., 2011). Combined with M1 muscarinic receptor-mediated effects on APP metabolism, it would confer AF710B a pharmacological profile of interest to tackle various pathological aspects of $\mathrm{AD}$.

AF710B can rescue synapse loss in vitro, while low doses of the compound can attenuate cognitive deficits and alleviate hallmarks of the established AD-like pathology in 3xTg-AD mice (Fisher et al., 2016). In order to validate the putative disease-modifying effect of the drug, AF710B was administered (in the micromolar range) per os daily to post-plaque McGillR-Thy1-APP rats for 5 months. Completion of the treatment was followed by a wash-out phase of 5 weeks, a unique experimental design key to discriminate true disease-modifying effects from symptomatic effects. The former should disappear after treatment cessation while the latter would be persistent (Ploeger and Holford, 2009). This treatment regimen was sufficient to fully restore cognition in the McGill tg rats. It also led to a substantial decrease in the production of cortical $A \beta$ and in the amount of mature amyloid plaques. Interestingly, the reduction in $A \beta$ load was accompanied by an increase in CSF A $\beta 42$ levels, suggesting that the drug could not only lower $A \beta$ production but also increase its clearance (Hall et al., 2018). Of note, this finding may be of translational value to non-invasively follow treatment response in a human population. Further to it, CNS inflammation was decreased, as mirrored by the abolishment of microglia recruitment toward $\mathrm{A} \beta$-burdened neurons in the hippocampus and the normalization of hippocampal Ibal protein levels and cortical IL-10 mRNA expression levels. Finally, these changes were accompanied by an increase in synaptophysin levels, suggesting possible synaptogenic activity (Hall et al., 2018).

In summary, with $\mathrm{M} 1 /$ sigma-1 activity as well as putative disease-modifying properties at very low dose, AF710B is well positioned for therapeutic interventions in $\mathrm{AD}$. The case of AF710B as detailed above provides interesting clues pertaining to potentially increasing the predictive value of preclinical studies.
In this particular case, results from the study in McGill-RThyl-APP tg rats complemented the initial findings of AF710B beneficial effects in trihexyphenidyl rats and tg mice, by offering new insights into the properties of the drug (Fisher et al., 2016; Hall et al., 2018). Such approach, where efficacy of a drug is validated in several models and under different conditions, should be encouraged before translation to human trials. This is particularly important considering that no single model can recapitulate all aspects of the human disease.

\section{GENERAL CONSIDERATIONS: TRANSLATIONAL VALUE OF EXPERIMENTAL PHARMACOLOGY IN RODENT MODELS}

Despite the growing list of compounds that have demonstrated positive therapeutic effects in tg rodent models, none of these experimental leads have yet reached FDA-approval for the treatment of $\mathrm{AD}$ in humans, highlighting a clear deficit in translational research. In line with these failures, the question that arises is: how can we better predict drug efficacy in humans based on animal studies?

Although tg APP rodent models have been instrumental in increasing our understanding of $\mathrm{A} \beta$-driven pathogenic processes in $\mathrm{AD}$, it is challenging to ascertain whether the phenotypes observed in these tg animals can be solely attributed to elevated $\mathrm{A} \beta$ levels or result from overexpression of APP. To address this concern, single humanized APP knock-in (KI) mice have been recently developed (Saito et al., 2014), paving the way toward more physiological models of the disease. Evidently, one of the main shortcomings of the current tg $\mathrm{AD}$ models is that they express genes carrying mutations seen in FAD, whereas most $\mathrm{AD}$ cases are sporadic. It remains an open question whether the findings obtained from FAD-like models can in fact be translated to heterogeneous sporadic cases, in which a multitude of susceptibility factors likely drive disease onset (genetic, environmental or lifestyle) (Rocchi et al., 2003; Mattson, 2004).

Mouse has been the species of choice since the inception of tg models, mostly for technical and economic reasons. Several characteristics unique to rats would, however, indicate that they may be better suited than mice for research relevant to humans, especially in the neuroscience field [reviewed in Do Carmo and Cuello (2013); Zimmer et al. (2014) and Ellenbroek and Youn (2016)]. Indeed, rats have a more complex CNS than mice and their brain development in postnatal life is more similar to humans than mice (Wood et al., 2003; Pressler and Auvin, 2013). Although the rat and mouse brains are anatomically similar, there are important functional differences between the two, including substantial differences in neuronal plasticity. For example, recent studies indicate that in adult rats, the rate of hippocampal neurogenesis is faster than in mice and new neurons are more likely to be recruited during learning than in mice (Snyder et al., 2009). Rats display a richer behavior including more complex social behavior (such a juvenile play) compared to mice, allowing 
for a larger range of cognitive analyses (Whishaw et al., 2001; Do Carmo and Cuello, 2013). Genetically, they also resemble humans more than mice do. For example, the rat apolipoprotein E (ApoE) gene bears more homology with human ApoE than mouse ApoE (Rajavashisth et al., 1985; Tran et al., 2013). This is of significance considering that polymorphism in ApoE is a strong genetic risk factor for $\mathrm{AD}$, with ApoE4 showing the strongest association with the disease (Poirier et al., 1993; Strittmatter et al., 1993; Roses et al., 1994). As the genetic toolbox for rats is growing, the number of tg rat models will likely increase in the future. Whether rat-based models will better predict the human condition and the efficacy of experimental therapeutics remains to be established.

One important aspect of current tg models is that they likely mimic early disease stage when the focus of most current clinical trials has been mild-moderate $\mathrm{AD}$. It is therefore highly likely that some of the therapeutic leads emerging from experimentation in $\mathrm{tg}$ mice and rats might have an important impact in slowing or diminishing the $\mathrm{AD}$ pathology at the preclinical stage. Such opportunity would have a consequential impact on the global $\mathrm{AD}$ prevalence since it has been estimated that a 5-year delay in the onset of clinical AD would decrease the total number of affected individuals by $50 \%$ at the end of a 25 year period (Alzheimer's Association, 2015). However, adequate identification and selection of human participants for such trials remains challenging and is pending on the discovery of novel biomarkers that can unequivocally identify preclinical $\mathrm{AD}$ stage. In the meantime, some clinical trials have been focusing on individuals with a high risk of developing $\mathrm{AD}$ dementia due to a family history of AD. These individuals have been recruited and enrolled before they develop any sign of cognitive decline (Cummings et al., 2018). Results from these ongoing prevention trials such as the DIAN-TU, DEPEND or HEART studies (which have enrolled individuals with a family history of autosomal dominant $\mathrm{AD}$, a family history of $\mathrm{AD}$ or a parental history of $\mathrm{AD}$, respectively) are highly anticipated and may indicate whether pharmacological interventions at preclinical AD stages could prevent or delay cognitive decline.

\section{CONCLUSION}

Over the past decades, our understanding of $\mathrm{AD}$ has grown tremendously, owing for a large part to the contribution of

\section{REFERENCES}

Aisen, P. S., Cummings, J., Jack, C. R. Jr., Morris, J. C., Sperling, R., Frölich, L., et al. (2017). On the path to 2025: understanding the Alzheimer's disease continuum. Alzheimers Res. Ther. 9:60. doi: 10.1186/s13195-017-0 283-5

Allen, B., Ingram, E., Takao, M., Smith, M. J., Jakes, R., Virdee, K., et al. (2002). Abundant tau filaments and nonapoptotic neurodegeneration in transgenic mice expressing human P301S tau protein. J. Neurosci. 22, 9340-9351. doi: 10.1523/JNEUROSCI.22-21-09340.2002

Alzheimer's Association (2015). Changing the Trajectory of Alzheimer's Disease: How Treatment by 2025 Saves Lives and Dollars. Chicago, IL: Alzheimer's Association, 1-16.

Alzheimer's Association (2018). Alzheimer's Disease Facts and Figures. Chicago, IL: Alzheimer's Association. tg models mimicking various aspects of the AD pathology. However, despite intensive research, there is still no cure for this devastating disease. As the prevalence of $\mathrm{AD}$ increases worldwide, it is crucial to identify bottlenecks in the drug development pipeline, which may slow down progress toward the market approval of promising drug candidates. The shortcomings of current tg models of AD are well-acknowledged by the research community. In response, there is a growing effort to provide better predictive animal models of the disease. Along these lines, current efforts toward the identification of biomarkers that would identify an ongoing $\mathrm{AD}$ process before clinical presentation will most likely culminate in refined clinical trial design. These initiatives are much needed to translate positive preclinical studies into efficacy in human clinical trials. An optimist outlook regarding successful preclinical studies is that they might offer novel therapeutic avenues with probable tangible benefits if applied at the earliest, preclinical stages of the disease. A favorable future scenario in which diagnosis of $\mathrm{AD}$ pathology is made about 10 years before dementia could help radically change the currently disappointing therapeutic arsenal.

\section{AUTHOR CONTRIBUTIONS}

ACC and $\mathrm{HH}$ designed the structure and contents of the review. All authors contributed to the writing of the manuscript.

\section{FUNDING}

This work was funded by the Canadian Institute of Health and Research Project Grant (201603PJT-364544) and the National Institute of Health and Aging Operating Grant (R01AG056850) to ACC.

\section{ACKNOWLEDGMENTS}

ACC is the holder of the Charles E. Frosst/Merck endowed Chair in Pharmacology and a member of the Canadian Consortium on Neurodegeneration in Aging. The authors are grateful for the unrestricted support provided by Merck Canada.

Ameen-Ali, K. E., Wharton, S. B., Simpson, J. E., Heath, P. R., Sharp, P., and Berwick, J. (2017). Review: neuropathology and behavioural features of transgenic murine models of Alzheimer's disease. Neuropathol. Appl. Neurobiol. 43, 553-570. doi: 10.1111/nan.12440

Azab, A. N., Shnaider, A., Osher, Y., Wang, D., Bersudsky, Y., and Belmaker, R. H. (2015). Lithium nephrotoxicity. Int. J. Bipolar Disord. 3:28. doi: 10.1186/ s40345-015-0028-y

Bakulski, K. M., Dolinoy, D. C., Sartor, M. A., Paulson, H. L., Konen, J. R., Lieberman, A. P., et al. (2012). Genome-wide DNA methylation differences between late-onset Alzheimer's disease and cognitively normal controls in human frontal cortex. J. Alzheimers Dis. 29, 571-588. doi: 10.3233/JAD-2012111223

Bales, K. R. (2012). The value and limitations of transgenic mouse models used in drug discovery for Alzheimer's disease: an update. Expert Opin. Drug Discov. 7, 281-297. doi: 10.1517/17460441.2012.666234 
Bateman, R. J., Aisen, P. S., De Strooper, B., Fox, N. C., Lemere, C. A., Ringman, J. M., et al. (2011). Autosomal-dominant Alzheimer's disease: a review and proposal for the prevention of Alzheimer's disease. Alzheimers Res. Ther. 3:1. doi: $10.1186 /$ alzrt59

Bottiglieri, T., Reynolds, E. H., Toone, B. K., and Carney, M. W. (1991). CSF S-adenosylmethionine in neuropsychiatric disorders. Lancet 338:121. doi: 10. 1016/0140-6736(91)90114-5

Breitner, J. C., Baker, L. D., Montine, T. J., Meinert, C. L., Lyketsos, C. G., Ashe, K. H., et al. (2011). Extended results of the Alzheimer's disease antiinflammatory prevention trial. Alzheimers Dement. 7, 402-411. doi: 10.1016/ j.jalz.2010.12.014

Caccamo, A., Oddo, S., Billings, L. M., Green, K. N., Martinez-Coria, H., Fisher, A., et al. (2006). M1 receptors play a central role in modulating AD-like pathology in transgenic mice. Neuron 49,671-682. doi: 10.1016/j.neuron.2006.01.020

Cadena-del-Castillo, C., Valdes-Quezada, C., Carmona-Aldana, F., Arias, C., Bermudez-Rattoni, F., and Recillas-Targa, F. (2014). Age-dependent increment of hydroxymethylation in the brain cortex in the triple-transgenic mouse model of Alzheimer's disease. J. Alzheimers Dis. 41, 845-854. doi: 10.3233/JAD-13 2285

Chouliaras, L., Mastroeni, D., Delvaux, E., Grover, A., Kenis, G., Hof, P. R., et al. (2013). Consistent decrease in global DNA methylation and hydroxymethylation in the hippocampus of Alzheimer's disease patients. Neurobiol. Aging 34, 2091-2099. doi: 10.1016/j.neurobiolaging.2013. 02.021

Cohen, R. M., Rezai-Zadeh, K., Weitz, T. M., Rentsendorj, A., Gate, D., Spivak, I., et al. (2013). A transgenic Alzheimer rat with plaques, tau pathology, behavioral impairment, oligomeric abeta, and frank neuronal loss. J. Neurosci. 33, 62456256. doi: 10.1523/JNEUROSCI.3672-12.2013

Cuello, A. C. (2017). Early and late CNS inflammation in Alzheimer's disease: two extremes of a continuum? Trends Pharmacol. Sci. 38, 956-966. doi: 10.1016/j. tips.2017.07.005

Cuello, A. C., Ferretti, M. T., and Iulita, M. F. (2012). Preplaque ('Preclinical') a beta-induced inflammation and nerve growth factor deregulation in transgenic models of Alzheimer's disease-like amyloid pathology. Neurodegener. Dis. 10, 104-107. doi: 10.1159/000333339

Cuello, A. C., Ferretti, M. T., Leon, W. C., Iulita, M. F., Melis, T., Ducatenzeiler, A., et al. (2010). Early-stage inflammation and experimental therapy in transgenic models of the Alzheimer-like amyloid pathology. Neurodegener. Dis. 7, 96-98. doi: 10.1159/000285514

Cummings, J., Lee, G., Ritter, A., and Zhong, K. (2018). Alzheimer's disease drug development pipeline: 2018. Alzheimers Dement. 4, 195-214. doi: 10.1016/j.trci. 2018.03.009

De Jager, P. L., Srivastava, G., Lunnon, K., Burgess, J., Schalkwyk, L. C., Yu, L., et al. (2014). Alzheimer's disease: early alterations in brain DNA methylation at ANK1, BIN1, RHBDF2 and other loci. Nat. Neurosci. 17, 1156-1163. doi: 10.1038/nn.3786

Derby, C. A., Katz, M. J., Lipton, R. B., and Hall, C. B. (2017). Trends in dementia incidence in a birth cohort analysis of the Einstein aging study. JAMA Neurol. 74, 1345-1351. doi: 10.1001/jamaneurol.2017.1964

Do Carmo, S., Crynen, G., Paradis, T., Reed, J., Iulita, M. F., Ducatenzeiler, A., et al. (2018). Hippocampal proteomic analysis reveals distinct pathway deregulation profiles at early and late stages in a rat model of Alzheimer's-like amyloid pathology. Mol. Neurobiol. 55, 3451-3476. doi: 10.1007/s12035-017-0580-9

Do Carmo, S., and Cuello, A. C. (2013). Modeling Alzheimer's disease in transgenic rats. Mol. Neurodegener. 8:37. doi: 10.1186/1750-1326-8-37

Do Carmo, S., Hanzel, C. E., Jacobs, M. L., Machnes, Z., Iulita, M. F., Yang, J., et al. (2016). Rescue of early bace-1 and global DNA demethylation by S-adenosylmethionine reduces amyloid pathology and improves cognition in an Alzheimer's model. Sci. Rep. 6:34051. doi: 10.1038/srep34051

Drummond, E., and Wisniewski, T. (2017). Alzheimer's disease: experimental models and reality. Acta Neuropathol. 133, 155-175. doi: 10.1007/s00401-0161662-x

Ellenbroek, B., and Youn, J. (2016). Rodent models in neuroscience research: is it a rat race? Dis. Model. Mech. 9, 1079-1087. doi: 10.1242/dmm.026120

Fajardo, V. A., Fajardo, V. A., LeBlanc, P. J., and MacPherson, R. E. K. (2018). Examining the relationship between trace lithium in drinking water and the rising rates of age-adjusted Alzheimer's disease mortality in Texas. J. Alzheimers Dis. 61, 425-434. doi: 10.3233/JAD-170744
Ferretti, M. T., Allard, S., Partridge, V., Ducatenzeiler, A., and Cuello, A. C. (2012a). Minocycline corrects early, pre-plaque neuroinflammation and inhibits BACE1 in a transgenic model of Alzheimer's disease-like amyloid pathology. J. Neuroinflammation 9:62. doi: 10.1186/1742-2094-9-62

Ferretti, M. T., Bruno, M. A., Ducatenzeiler, A., Klein, W. L., and Cuello, A. C. (2012b). Intracellular Abeta-oligomers and early inflammation in a model of Alzheimer's disease. Neurobiol. Aging 33, 1329-1342. doi: 10.1016/j. neurobiolaging.2011.01.007

Ferretti, M. T., Partridge, V., Leon, W. C., Canneva, F., Allard, S., Arvanitis, D. N., et al. (2011). Transgenic mice as a model of pre-clinical Alzheimer's disease. Curr. Alzheimer Res. 8, 4-23. doi: 10.2174/156720511794604561

Filipiak, W. E., and Saunders, T. L. (2006). Advances in transgenic rat production. Transgenic Res. 15, 673-686. doi: 10.1007/s11248-006-9002-x

Fisher, A. (2008). Cholinergic treatments with emphasis on $\mathrm{ml}$ muscarinic agonists as potential disease-modifying agents for Alzheimer's disease. Neurotherapeutics 5, 433-442. doi: 10.1016/j.nurt.2008.05.002

Fisher, A. (2012). Cholinergic modulation of amyloid precursor protein processing with emphasis on M1 muscarinic receptor: perspectives and challenges in treatment of Alzheimer's disease. J. Neurochem. 120(Suppl. 1), 22-33. doi: 10. 1111/j.1471-4159.2011.07507.x

Fisher, A., Bezprozvanny, I., Wu, L., Ryskamp, D. A., Bar-Ner, N., Natan, N., et al. (2016). AF710B, a novel M1/sigmal agonist with therapeutic efficacy in animal models of Alzheimer's disease. Neurodegener. Dis. 16, 95-110. doi: $10.1159 / 000440864$

Forlenza, O. V., Aprahamian, I., de Paula, V. J., and Hajek, T. (2016). Lithium, a therapy for $\mathrm{AD}$ : current evidence from clinical trials of neurodegenerative disorders. Curr. Alzheimer Res. 13, 879-886. doi: 10.2174/ 1567205013666160219112854

Forlenza, O. V., Diniz, B. S., Radanovic, M., Santos, F. S., Talib, L. L., and Gattaz, W. F. (2011). Disease-modifying properties of long-term lithium treatment for amnestic mild cognitive impairment: randomised controlled trial. $\mathrm{Br}$. J. Psychiatry 198, 351-356. doi: 10.1192/bjp.bp.110.080044

Galeano, P., Leal, M. C., Ferrari, C. C., Dalmasso, M. C., Martino Adami, P. V., Farias, M. I., et al. (2018). Chronic hippocampal expression of notch intracellular domain induces vascular thickening, reduces glucose availability, and exacerbates spatial memory deficits in a rat model of early Alzheimer. Mol. Neurobiol. 55, 8637-8650. doi: 10.1007/s12035-018-1002-3

Galeano, P., Martino Adami, P. V., Do Carmo, S., Blanco, E., Rotondaro, C., Capani, F., et al. (2014). Longitudinal analysis of the behavioral phenotype in a novel transgenic rat model of early stages of Alzheimer's disease. Front. Behav. Neurosci. 8:321. doi: 10.3389/fnbeh.2014.00321

Games, D., Adams, D., Alessandrini, R., Barbour, R., Berthelette, P., Blackwell, C., et al. (1995). Alzheimer-type neuropathology in transgenic mice overexpressing V717F beta-amyloid precursor protein. Nature 373, 523-527. doi: 10.1038/ $373523 \mathrm{a} 0$

Gelenberg, A. J., and Jefferson, J. W. (1995). Lithium tremor. J. Clin. Psychiatry 56, 283-287.

Gotz, J., Deters, N., Doldissen, A., Bokhari, L., Ke, Y., Wiesner, A., et al. (2007). A decade of tau transgenic animal models and beyond. Brain Pathol. 17, 91-103. doi: 10.1111/j.1750-3639.2007.00051.x

Hall, H., Iulita, M. F., Gubert, P., Flores Aguilar, L., Ducatenzeiler, A., Fisher, A., et al. (2018). AF710B, an M1/sigma-1 receptor agonist with long-lasting disease-modifying properties in a transgenic rat model of Alzheimer's disease. Alzheimers Dement. 14, 811-823. doi: 10.1016/j.jalz.2017.11.009

Hampel, H., Ewers, M., Burger, K., Annas, P., Mortberg, A., Bogstedt, A., et al. (2009). Lithium trial in Alzheimer's disease: a randomized, single-blind, placebo-controlled, multicenter 10-week study. J. Clin. Psychiatry 70, 922-931. doi: 10.4088/JCP.08m04606

Hanzel, C. E., Pichet-Binette, A., Pimentel, L. S., Iulita, M. F., Allard, S., Ducatenzeiler, A., et al. (2014). Neuronal driven pre-plaque inflammation in a transgenic rat model of Alzheimer's disease. Neurobiol. Aging 35, 2249-2262. doi: 10.1016/j.neurobiolaging.2014.03.026

Hardy, J., Bogdanovic, N., Winblad, B., Portelius, E., Andreasen, N., CedazoMinguez, A., et al. (2014). Pathways to Alzheimer's disease. J. Intern. Med. 275, 296-303. doi: 10.1111/joim.12192

Havens, W. W. II, and Cole, J. (1982). Successful treatment of dementia with lithium. J. Clin. Psychopharmacol. 2, 71-72. doi: 10.1097/00004714-19820200000013 
Heggland, I., Storkaas, I. S., Soligard, H. T., Kobro-Flatmoen, A., and Witter, M. P. (2015). Stereological estimation of neuron number and plaque load in the hippocampal region of a transgenic rat model of Alzheimer's disease. Eur. J. Neurosci. 41, 1245-1262. doi: 10.1111/ejn.12876

Hickman, R. A., Faustin, A., and Wisniewski, T. (2016). Alzheimer disease and its growing epidemic: risk factors, biomarkers, and the urgent need for therapeutics. Neurol. Clin. 34, 941-953. doi: 10.1016/j.ncl.2016.06.009

Holcomb, L., Gordon, M. N., McGowan, E., Yu, X., Benkovic, S., Jantzen, P., et al. (1998). Accelerated Alzheimer-type phenotype in transgenic mice carrying both mutant amyloid precursor protein and presenilin 1 transgenes. Nat. Med. 4, 97-100. doi: 10.1038/nm0198-097

Hsiao, K. (1998). Transgenic mice expressing Alzheimer amyloid precursor proteins. Exp. Gerontol. 33, 883-889. doi: 10.1016/S0531-5565(98)00045-X

Hsiao, K., Chapman, P., Nilsen, S., Eckman, C., Harigaya, Y., Younkin, S., et al. (1996). Correlative memory deficits, Abeta elevation, and amyloid plaques in transgenic mice. Science 274, 99-102. doi: 10.1126/science.274.5284.99

Iulita, M. F., Allard, S., Richter, L., Munter, L.-M., Ducatenzeiler, A., Weise, C., et al. (2014). Intracellular $A \beta$ pathology and early cognitive impairments in a transgenic rat overexpressing human amyloid precursor protein: a multidimensional study. Acta Neuropathol. Commun. 2:61. doi: 10.1186/20515960-2-61

Iulita, M. F., Bistue Millon, M. B., Pentz, R., Aguilar, L. F., Do Carmo, S., Allard, S., et al. (2017). Differential deregulation of NGF and BDNF neurotrophins in a transgenic rat model of Alzheimer's disease. Neurobiol. Dis. 108, 307-323. doi: $10.1016 /$ j.nbd.2017.08.019

Iulita, M. F., and Cuello, A. C. (2016). The NGF metabolic pathway in the CNS and its dysregulation in down syndrome and Alzheimer's disease. Curr. Alzheimer Res. 13, 53-67. doi: 10.2174/1567205012666150921100030

Iwata, A., Nagata, K., Hatsuta, H., Takuma, H., Bundo, M., Iwamoto, K., et al. (2014). Altered CpG methylation in sporadic Alzheimer's disease is associated with APP and MAPT dysregulation. Hum. Mol. Genet. 23, 648-656. doi: 10. 1093/hmg/ddt451

Jankowsky, J. L., and Zheng, H. (2017). Practical considerations for choosing a mouse model of Alzheimer's disease. Mol. Neurodegener. 12:89. doi: 10.1186/ s13024-017-0231-7

Janus, C., Pearson, J., McLaurin, J., Mathews, P. M., Jiang, Y., Schmidt, S. D., et al. (2000). A beta peptide immunization reduces behavioural impairment and plaques in a model of Alzheimer's disease. Nature 408, 979-982. doi: 10.1038/ 35050110

Jaturapatporn, D., Isaac, M. G., McCleery, J., and Tabet, N. (2012). Aspirin, steroidal and non-steroidal anti-inflammatory drugs for the treatment of Alzheimer's disease. Cochrane Database Syst. Rev. 2:CD006378. doi: 10.1002/ 14651858.CD006378.pub2

Kessing, L. V., Gerds, T. A., Knudsen, N. N., Jorgensen, L. F., Kristiansen, S. M., Voutchkova, D., et al. (2017). Association of lithium in drinking water with the incidence of dementia. JAMA Psychiatry 74, 1005-1010. doi: 10.1001/ jamapsychiatry.2017.2362

Kinoshita, J., and Clark, T. (2007). Alzforum. Methods Mol. Biol. 401, 365-381. doi: 10.1007/978-1-59745-520-6_19

LaFerla, F. M., and Green, K. N. (2012). Animal models of Alzheimer disease. Cold Spring Harb. Perspect. Med. 2:a006320. doi: 10.1101/cshperspect.a00 6320

Langa, K. M. (2015). Is the risk of Alzheimer's disease and dementia declining? Alzheimers Res. Ther. 7:34. doi: 10.1186/s13195-015-0118-1

Leon, W. C., Canneva, F., Partridge, V., Allard, S., Ferretti, M. T., DeWilde, A., et al. (2010). A novel transgenic rat model with a full Alzheimer's-like amyloid pathology displays pre-plaque intracellular amyloid- $\beta$-associated cognitive impairment. J. Alzheimers Dis. 20, 113-126. doi: 10.3233/JAD-2010-1349

Leyhe, T., Eschweiler, G. W., Stransky, E., Gasser, T., Annas, P., Basun, H., et al. (2009). Increase of BDNF serum concentration in lithium treated patients with early Alzheimer's disease. J. Alzheimers Dis. 16, 649-656. doi: 10.3233/JAD2009-1004

Livingstone, C., and Rampes, H. (2006). Lithium: a review of its metabolic adverse effects. J. Psychopharmacol. 20, 347-355. doi: 10.1177/0269881105057515

Macdonald, A., Briggs, K., Poppe, M., Higgins, A., Velayudhan, L., and Lovestone, S. (2008). A feasibility and tolerability study of lithium in Alzheimer's disease. Int. J. Geriatr. Psychiatry 23, 704-711. doi: 10.1002/gps. 1964
Malhi, G. S., and Outhred, T. (2016). Therapeutic mechanisms of lithium in bipolar disorder: recent advances and current understanding. CNS Drugs 30, 931-949. doi: 10.1007/s40263-016-0380-1

Marrazzo, A., Caraci, F., Salinaro, E. T., Su, T. P., Copani, A., and Ronsisvalle, G. (2005). Neuroprotective effects of sigma-1 receptor agonists against betaamyloid-induced toxicity. Neuroreport 16, 1223-1226. doi: 10.1097/00001756200508010-00018

Martino Adami, P. V., Galeano, P., Wallinger, M. L., Quijano, C., Rabossi, A., Pagano, E. S., et al. (2017a). Worsening of memory deficit induced by energydense diet in a rat model of early-Alzheimer's disease is associated to neurotoxic Abeta species and independent of neuroinflammation. Biochim. Biophys. Acta 1863, 731-743. doi: 10.1016/j.bbadis.2016.12.014

Martino Adami, P. V., Quijano, C., Magnani, N., Galeano, P., Evelson, P., Cassina, A., et al. (2017b). Synaptosomal bioenergetic defects are associated with cognitive impairment in a transgenic rat model of early Alzheimer's disease. J. Cereb. Blood Flow Metab. 37, 69-84. doi: 10.1177/0271678X15615132

Mastroeni, D., Grover, A., Delvaux, E., Whiteside, C., Coleman, P. D., and Rogers, J. (2010). Epigenetic changes in Alzheimer's disease: decrements in DNA methylation. Neurobiol. Aging 31, 2025-2037. doi: 10.1016/j.neurobiolaging. 2008.12.005

Mattson, M. P. (2004). Pathways towards and away from Alzheimer's disease. Nature 430, 631-639. doi: 10.1038/nature02621

Mauer, S., Vergne, D., and Ghaemi, S. N. (2014). Standard and trace-dose lithium: a systematic review of dementia prevention and other behavioral benefits. Aust. N. Z. J. Psychiatry 48, 809-818. doi: 10.1177/0004867414536932

Maurice, T., and Su, T. P. (2009). The pharmacology of sigma-1 receptors. Pharmacol. Ther. 124, 195-206. doi: 10.1016/j.pharmthera.2009.07.001

McGeer, P. L., McGeer, E., Rogers, J., and Sibley, J. (1990). Anti-inflammatory drugs and Alzheimer disease. Lancet 335:1037. doi: 10.1016/0140-6736(90)91101-F

McGeer, P. L., and McGeer, E. G. (2013). The amyloid cascade-inflammatory hypothesis of Alzheimer disease: implications for therapy. Acta Neuropathol. 126, 479-497. doi: 10.1007/s00401-013-1177-7

McGeer, P. L., and Rogers, J. (1992). Anti-inflammatory agents as a therapeutic approach to Alzheimer's disease. Neurology 42, 447-449. doi: 10.1212/WNL.42. 2.447

McGrath, J. J., and Berk, M. (2017). Could lithium in drinking water reduce the incidence of dementia? JAMA Psychiatry 74, 983-984. doi: 10.1001/ jamapsychiatry.2017.2336

Morgan, D., Diamond, D. M., Gottschall, P. E., Ugen, K. E., Dickey, C., Hardy, J., et al. (2000). A beta peptide vaccination prevents memory loss in an animal model of Alzheimer's disease. Nature 408, 982-985. doi: 10.1038/35050116

Morris, G., and Berk, M. (2016). The putative use of lithium in Alzheimer's disease. Curr. Alzheimer Res. 13, 853-861. doi: 10.2174/1567205013666160219113112

Morrison, L. D., Smith, D. D., and Kish, S. J. (1996). Brain S-adenosylmethionine levels are severely decreased in Alzheimer's disease. J. Neurochem. 67, 13281331. doi: 10.1046/j.1471-4159.1996.67031328.x

Mucke, L., Masliah, E., Yu, G. Q., Mallory, M., Rockenstein, E. M., Tatsuno, G., et al. (2000). High-level neuronal expression of abeta 1-42 in wild-type human amyloid protein precursor transgenic mice: synaptotoxicity without plaque formation. J. Neurosci. 20, 4050-4058. doi: 10.1523/JNEUROSCI.20-11-04050. 2000

Mullan, M., Crawford, F., Axelman, K., Houlden, H., Lilius, L., Winblad, B., et al. (1992). A pathogenic mutation for probable Alzheimer's disease in the APP gene at the N-terminus of beta-amyloid. Nat. Genet. 1, 345-347. doi: 10.1038/ ng0892-345

Murrell, J., Farlow, M., Ghetti, B., and Benson, M. D. (1991). A mutation in the amyloid precursor protein associated with hereditary Alzheimer's disease. Science 254, 97-99. doi: 10.1126/science.1925564

Nicolia, V., Cavallaro, R. A., Lopez-Gonzalez, I., Maccarrone, M., Scarpa, S., Ferrer, I., et al. (2017). DNA methylation profiles of selected pro-inflammatory cytokines in Alzheimer disease. J. Neuropathol. Exp. Neurol. 76, 27-31. doi: 10.1093/jnen/nlw099

Nilsen, L. H., Melo, T. M., Saether, O., Witter, M. P., and Sonnewald, U. (2012). Altered neurochemical profile in the McGill-R-Thy1-APP rat model of Alzheimer's disease: a longitudinal in vivo $1 \mathrm{H}$ MRS study. J. Neurochem. 123, 532-541. doi: 10.1111/jnc. 12003

Nilsen, L. H., Melo, T. M., Witter, M. P., and Sonnewald, U. (2014a). Early differences in dorsal hippocampal metabolite levels in males but not females 
in a transgenic rat model of Alzheimer's disease. Neurochem. Res. 39, 305-312. doi: 10.1007/s11064-013-1222-x

Nilsen, L. H., Witter, M. P., and Sonnewald, U. (2014b). Neuronal and astrocytic metabolism in a transgenic rat model of Alzheimer's disease. J. Cereb. Blood Flow Metab. 34, 906-914. doi: 10.1038/jcbfm.2014.37

Nitsch, R. M., Slack, B. E., Wurtman, R. J., and Growdon, J. H. (1992). Release of Alzheimer amyloid precursor derivatives stimulated by activation of muscarinic acetylcholine receptors. Science 258, 304-307. doi: 10.1126/science.1411529

Nunes, M. A., Schowe, N. M., Monteiro-Silva, K. C., Baraldi-Tornisielo, T., Souza, S. I., Balthazar, J., et al. (2015). Chronic microdose lithium treatment prevented memory loss and neurohistopathological changes in a transgenic mouse model of Alzheimer's disease. PLoS One 10:e0142267. doi: 10.1371/ journal.pone.0142267

Nunes, M. A., Viel, T. A., and Buck, H. S. (2013). Microdose lithium treatment stabilized cognitive impairment in patients with Alzheimer's disease. Curr. Alzheimer Res. 10, 104-107.

Oakley, H., Cole, S. L., Logan, S., Maus, E., Shao, P., Craft, J., et al. (2006). Intraneuronal beta-amyloid aggregates, neurodegeneration, and neuron loss in transgenic mice with five familial Alzheimer's disease mutations: potential factors in amyloid plaque formation. J. Neurosci. 26, 10129-10140. doi: 10.1523/ JNEUROSCI.1202-06.2006

Oddo, S., Caccamo, A., Shepherd, J. D., Murphy, M. P., Golde, T. E., Kayed, R., et al. (2003). Triple-transgenic model of Alzheimer's disease with plaques and tangles: intracellular Abeta and synaptic dysfunction. Neuron 39, 409-421. doi: 10.1016/S0896-6273(03)00434-3

Orgogozo, J. M., Gilman, S., Dartigues, J. F., Laurent, B., Puel, M., Kirby, L. C., et al. (2003). Subacute meningoencephalitis in a subset of patients with AD after Abeta42 immunization. Neurology 61, 46-54. doi: 10.1212/01.WNL. 0000073623.84147.A8

Parent, M. J., Zimmer, E. R., Shin, M., Kang, M. S., Fonov, V. S., Mathieu, A., et al. (2017). Multimodal imaging in rat model recapitulates Alzheimer's disease biomarkers abnormalities. J. Neurosci. 37, 12263-12271. doi: 10.1523/ JNEUROSCI.1346-17.2017

Pimentel, L. S., Allard, S., Do Carmo, S., Weinreb, O., Danik, M., Hanzel, C. E., et al. (2015). The multi-target drug M30 shows pro-cognitive and anti-inflammatory effects in a rat model of Alzheimer's disease. J. Alzheimers Dis. 47, 373-383. doi: $10.3233 /$ JAD- 143126

Ploeger, B. A., and Holford, N. H. (2009). Washout and delayed start designs for identifying disease modifying effects in slowly progressive diseases using disease progression analysis. Pharm. Stat. 8, 225-238. doi: 10.1002/pst.355

Poirier, J., Davignon, J., Bouthillier, D., Kogan, S., Bertrand, P., and Gauthier, S. (1993). Apolipoprotein E polymorphism and Alzheimer's disease. Lancet 342, 697-699. doi: 10.1016/0140-6736(93)91705-Q

Pressler, R., and Auvin, S. (2013). Comparison of brain maturation among species: an example in translational research suggesting the possible use of bumetanide in newborn. Front. Neurol. 4:36. doi: 10.3389/fneur.2013.00036

Prestia, F. A., Galeano, P., Martino Adami, P. V., Do Carmo, S., Castano, E. M., Cuello, A. C., et al. (2018). Platelets bioenergetics screening reflects the impact of brain abeta plaque accumulation in a rat model of alzheimer. Neurochem. Res. doi: 10.1007/s11064-018-2657-x [Epub ahead of print].

Puzzo, D., Gulisano, W., Palmeri, A., and Arancio, O. (2015). Rodent models for Alzheimer's disease drug discovery. Expert Opin. Drug Discov. 10, 703-711. doi: 10.1517/17460441.2015.1041913

Qi, Y., Klyubin, I., Cuello, A. C., and Rowan, M. J. (2018). NLRP3-dependent synaptic plasticity deficit in an Alzheimer's disease amyloidosis model in vivo. Neurobiol. Dis. 114, 24-30. doi: 10.1016/j.nbd.2018.02.016

Qi, Y., Klyubin, I., Harney, S. C., Hu, N., Cullen, W. K., Grant, M. K., et al. (2014). Longitudinal testing of hippocampal plasticity reveals the onset and maintenance of endogenous human Ass-induced synaptic dysfunction in individual freely behaving pre-plaque transgenic rats: rapid reversal by anti-Ass agents. Acta Neuropathol. Commun. 2:175. doi: 10.1186/s40478-014-0175-x

Rajavashisth, T. B., Kaptein, J. S., Reue, K. L., and Lusis, A. J. (1985). Evolution of apolipoprotein E: mouse sequence and evidence for an 11-nucleotide ancestral unit. Proc. Natl. Acad. Sci. U.S.A. 82, 8085-8089. doi: 10.1073/pnas.82.23. 8085

Rocchi, A., Pellegrini, S., Siciliano, G., and Murri, L. (2003). Causative and susceptibility genes for Alzheimer's disease: a review. Brain Res. Bull. 61, 1-24. doi: 10.1016/S0361-9230(03)00067-4
Rogers, J. (2018). Principles for central nervous system inflammation research: a call for a consortium approach. Alzheimers Dement. 14, 1553-1559. doi: 10.1016/j.jalz.2018.01.008

Roses, A. D., Strittmatter, W. J., Pericak-Vance, M. A., Corder, E. H., Saunders, A. M., and Schmechel, D. E. (1994). Clinical application of apolipoprotein E genotyping to Alzheimer's disease. Lancet 343, 1564-1565. doi: 10.1016/S01406736(94)92960-2

Ryman, D. C., Acosta-Baena, N., Aisen, P. S., Bird, T., Danek, A., Fox, N. C., et al. (2014). Symptom onset in autosomal dominant Alzheimer disease: a systematic review and meta-analysis. Neurology 83, 253-260. doi: 10.1212/ WNL.0000000000000596

Saito, T., Matsuba, Y., Mihira, N., Takano, J., Nilsson, P., Itohara, S., et al. (2014). Single App knock-in mouse models of Alzheimer's disease. Nat. Neurosci. 17, 661-663. doi: 10.1038/nn.3697

Sasaguri, H., Nilsson, P., Hashimoto, S., Nagata, K., Saito, T., De Strooper, B., et al. (2017). APP mouse models for Alzheimer's disease preclinical studies. EMBO J. 36, 2473-2487. doi: 10.15252/embj.201797397

Schenk, D., Barbour, R., Dunn, W., Gordon, G., Grajeda, H., Guido, T., et al. (1999). Immunization with amyloid-beta attenuates Alzheimer-disease-like pathology in the PDAPP mouse. Nature 400, 173-177. doi: 10.1038/22124

Seabrook, T. J., Jiang, L., Maier, M., and Lemere, C. A. (2006). Minocycline affects microglia activation, Abeta deposition, and behavior in APP-tg mice. Glia 53, 776-782. doi: 10.1002/glia.20338

Seblova, D., Quiroga, M. L., Fors, S., Johnell, K., Lovden, M., de Leon, A. P., et al. (2018). Thirty-year trends in dementia: a nationwide population study of Swedish inpatient records. Clin. Epidemiol. 10, 1679-1693. doi: 10.2147/CLEP. S178955

Sharma, A., Gerbarg, P., Bottiglieri, T., Massoumi, L., Carpenter, L. L., Lavretsky, H., et al. (2017). S-adenosylmethionine (SAMe) for neuropsychiatric disorders: a clinician-oriented review of research. J. Clin. Psychiatry 78, e656-e667. doi: 10.4088/JCP.16r11113

Smith, A. R., Smith, R. G., Condliffe, D., Hannon, E., Schalkwyk, L., Mill, J., et al. (2016). Increased DNA methylation near TREM2 is consistently seen in the superior temporal gyrus in Alzheimer's disease brain. Neurobiol. Aging 47, 35-40. doi: 10.1016/j.neurobiolaging.2016.07.008

Snyder, J. S., Choe, J. S., Clifford, M. A., Jeurling, S. I., Hurley, P., Brown, A., et al. (2009). Adult-born hippocampal neurons are more numerous, faster maturing, and more involved in behavior in rats than in mice. J. Neurosci. 29, 14484-14495. doi: 10.1523/JNEUROSCI.1768-09.2009

Spires, T. L., and Hyman, B. T. (2005). Transgenic models of Alzheimer's disease: learning from animals. NeuroRx 2, 423-437. doi: 10.1602/neurorx.2.3.423

Strittmatter, W. J., Saunders, A. M., Schmechel, D., Pericak-Vance, M., Enghild, J., Salvesen, G. S., et al. (1993). Apolipoprotein E: high-avidity binding to betaamyloid and increased frequency of type 4 allele in late-onset familial Alzheimer disease. Proc. Natl. Acad. Sci. U.S.A. 90, 1977-1981. doi: 10.1073/pnas.90.5.1977

Terao, T., Nakano, H., Inoue, Y., Okamoto, T., Nakamura, J., and Iwata, N. (2006). Lithium and dementia: a preliminary study. Prog. Neuropsychopharmacol. Biol. Psychiatry 30, 1125-1128. doi: 10.1016/j.pnpbp.2006.04.020

Tosto, G., and Reitz, C. (2013). Genome-wide association studies in Alzheimer's disease: a review. Curr. Neurol. Neurosci. Rep. 13:381. doi: 10.1007/s11910-0130381-0

Tran, T. N., Kim, S. H., Gallo, C., Amaya, M., Kyees, J., and Narayanaswami, V. (2013). Biochemical and biophysical characterization of recombinant rat apolipoprotein E: similarities to human apolipoprotein E3. Arch. Biochem. Biophys. 529, 18-25. doi: 10.1016/j.abb.2012.10.007

Villard, V., Espallergues, J., Keller, E., Vamvakides, A., and Maurice, T. (2011). Anti-amnesic and neuroprotective potentials of the mixed muscarinic receptor/sigma 1 (sigma1) ligand ANAVEX2-73, a novel aminotetrahydrofuran derivative. J. Psychopharmacol. 25, 1101-1117. doi: 10.1177/0269881110379286

West, R. L., Lee, J. M., and Maroun, L. E. (1995). Hypomethylation of the amyloid precursor protein gene in the brain of an Alzheimer's disease patient. J. Mol. Neurosci. 6, 141-146. doi: 10.1007/BF02736773

Whishaw, I. Q., Metz, G. A., Kolb, B., and Pellis, S. M. (2001). Accelerated nervous system development contributes to behavioral efficiency in the laboratory mouse: a behavioral review and theoretical proposal. Dev. Psychobiol. 39, 151-170. doi: 10.1002/dev.1041

Wilson, E. N., Abela, A. R., Do Carmo, S., Allard, S., Marks, A. R., Welikovitch, L. A., et al. (2017a). Intraneuronal amyloid beta accumulation disrupts 
hippocampal CRTC1-dependent gene expression and cognitive function in a rat model of Alzheimer disease. Cereb. Cortex 27, 1501-1511. doi: 10.1093/cercor/ bhv332

Wilson, E. N., Do Carmo, S., Iulita, M. F., Hall, H., Ducatenzeiler, A., Marks, A. R., et al. (2017b). BACE1 inhibition by microdose lithium formulation NP03 rescues memory loss and early stage amyloid neuropathology. Transl. Psychiatry 7:e1190. doi: 10.1038/tp.2017.169

Wilson, E. N., Do Carmo, S., Iulita, M. F., Hall, H., Austin, G. L., Jia, D. T., et al. (2018). Microdose lithium NP03 diminishes pre-plaque oxidative damage and neuroinflammation in a rat model of Alzheimer's-like amyloidosis. Curr. Alzheimer Res. 15, 1220-1230. doi: 10.2174/1567205015666180904154446

Wood, S. L., Beyer, B. K., and Cappon, G. D. (2003). Species comparison of postnatal CNS development: functional measures. Birth Defects Res. B Dev. Reprod. Toxicol. 68, 391-407. doi: 10.1002/bdrb.10037

Yoshiyama, Y., Higuchi, M., Zhang, B., Huang, S. M., Iwata, N., Saido, T. C., et al. (2007). Synapse loss and microglial activation precede tangles in a P301S tauopathy mouse model. Neuron 53, 337-351. doi: 10.1016/j.neuron.2007. 01.010

Zhang, C., Wang, Y., Wang, D., Zhang, J., and Zhang, F. (2018). NSAID exposure and risk of Alzheimer's disease: an updated meta-analysis from cohort studies. Front. Aging Neurosci. 10:83. doi: 10.3389/fnagi.2018.00083

Zhang, D., Qi, Y., Klyubin, I., Ondrejcak, T., Sarell, C. J., Cuello, A. C., et al. (2017). Targeting glutamatergic and cellular prion protein mechanisms of amyloid beta-mediated persistent synaptic plasticity disruption: longitudinal studies. Neuropharmacology 121, 231-246. doi: 10.1016/j.neuropharm.2017.03.036

Zhao, J., Zhu, Y., Yang, J., Li, L., Wu, H., De Jager, P. L., et al. (2017). A genome-wide profiling of brain DNA hydroxymethylation in Alzheimer's disease. Alzheimers Dement. 13, 674-688. doi: 10.1016/j.jalz.2016.10.004

Zhao, L., Gong, N., Liu, M., Pan, X., Sang, S., Sun, X., et al. (2014). Beneficial synergistic effects of microdose lithium with pyrroloquinoline quinone in an Alzheimer's disease mouse model. Neurobiol. Aging 35, 2736-2745. doi: 10. 1016/j.neurobiolaging.2014.06.003

Zimmer, E. R., Parent, M. J., Cuello, A. C., Gauthier, S., and Rosa-Neto, P. (2014). MicroPET imaging and transgenic models: a blueprint for Alzheimer's disease clinical research. Trends Neurosci. 37, 629Ü641. doi: 10.1016/j.tins.2014.07.002

Conflict of Interest Statement: The authors declare that the research was conducted in the absence of any commercial or financial relationships that could be construed as a potential conflict of interest.

Copyright (C) 2019 Cuello, Hall and Do Carmo. This is an open-access article distributed under the terms of the Creative Commons Attribution License (CC BY). The use, distribution or reproduction in other forums is permitted, provided the original author(s) and the copyright owner(s) are credited and that the original publication in this journal is cited, in accordance with accepted academic practice. No use, distribution or reproduction is permitted which does not comply with these terms. 